\title{
Mast Cells and Th17 Cells Contribute to the Lymphoma-Associated Pro-Inflammatory Microenvironment of Angioimmunoblastic T-Cell Lymphoma
}

\author{
Claudio Tripodo, ${ }^{*}$ Giorgia Gri, ${ }^{\dagger}$ \\ Pier Paolo Piccaluga, ${ }^{\ddagger}$ Barbara Frossi, ${ }^{\dagger}$ \\ Carla Guarnotta, ${ }^{*}$ Silvia Piconese, ${ }^{\S}$ \\ Giovanni Franco, "Valeria Vetri," \\ Carlo Ennio Pucillo, ${ }^{\dagger}$ Ada Maria Florena, ${ }^{*}$ \\ Mario Paolo Colombo, ${ }^{\S}$ and Stefano Aldo Pileri ${ }^{\ddagger}$ \\ From the Department of Human Pathology,* University of \\ Palermo, Palermo; the Immunology Section, ${ }^{\dagger}$ Department of \\ Biomedical Science and Technology, University of Udine, Udine; \\ the Department of Hematology and Oncological Sciences, ${ }^{*}$ \\ "L. e A. Seràgnoli" Bologna University School of Medicine, Bologna; \\ the Molecular Immunology Unit, ${ }^{\S}$ Department of Experimental \\ Oncology, Fondazione Istituto di Ricovero e Cura a Carattere \\ Scientifico (IRCCS) "Istituto Nazionale dei Tumori," Milan; and \\ the Hematology Unit, " Departments of Oncology and \\ Hematology and Physical and Astronomical Sciences," \\ University of Palermo, Palermo, Italy
}

Reports focusing on the immunological microenvironment of peripheral T-cell lymphomas (PTCL) are rare. Here we studied the reciprocal contribution of regulatory (Treg) and interleukin-17-producing (Th17) T-cells to the composition of the lymphomaassociated microenvironment of angioimmunoblastic T-cell lymphoma (AITL) and PTCL not otherwise specified on tissue microarrays from 30 PTCLs not otherwise specified and 37 AITLs. We found that Th17 but not Treg cells were differently represented in the two lymphomas and correlated with the amount of mast cells (MCs) and granulocytes, which preferentially occurred in the cellular milieu of AITL cases. We observed that MCs directly synthesized interleukin-6 and thus contribute to the establishment of a proinflammatory, Th17 permissive environment in AITL. We further hypothesized that the AITL clone itself could be responsible for the preferential accumulation of MCs at sites of infiltration through the synthesis of CXCL-13 and its interaction with the CXCR3 and CXCR5 receptors expressed on MCs. Consistent with this hypothesis, we observed MCs efficiently migrating in response to CXCL-13. On these bases, we conclude that MCs have a role in molding the immunological microenvironment of AITL toward the maintenance of pro-inflammatory conditions prone to Th17 generation and autoimmunity. (Am J Pathol 2010, 177:792-802; DOI: 10.2353/ajpath.2010.091286)

T-cell neoplasms remain largely obscure due to their relatively low prevalence and little knowledge of their pathobiology. ${ }^{1}$ Studies on peripheral T-cell lymphomas (PTCL) have focused on the identification of their normal counterparts, clone-specific signatures and clone-related molecules with possible prognostic and/or therapeutic relevance..$^{2-4}$ By contrast, few studies have investigated the T-cell lymphoma-associated microenvironment with the aim of finding diagnostic criteria to distinguish the various PTCL. ${ }^{5-7}$

Among PTCL, PTCL not otherwise specified (PTCL/ NOS) and angioimmunoblastic T-cell lymphoma (AITL) are the most common entities presenting with lymph node involvement. ${ }^{8}$ Although both forms are characterized by a dismal prognosis and poor response to standard chemotherapy, their distinction is mandatory because different targets for specific therapies have been recently proposed. ${ }^{9}$

According to the gene-expression profile of neoplastic clones, a follicular helper T-cell (Tfh)-related signature

Supported by grants from the Associazione Italiana Ricerca contro it Cancro (AIRC, Milan, Italy)

Accepted for publication April 22, 2010.

Supplemental material for this article can be found on http://ajp. amjpathol.org

Address reprint requests to Mario Paolo Colombo, Ph.D., Head Molecular Immunology Unit, Department of Experimental Oncology, Fondazione IRCCS Istituto Nazionale dei Tumori, Via Amadeo,42, 20133 Milano, Italy; or Stefano Aldo Pileri, M.D., Department of Hematology and Oncological Sciences "L. e A. Seràgnoli," Bologna University School of Medicine, Via Massarenti 9, 40138, Bologna, Italy. E-mail: mario.colombo@istitutotumori. mi.it or stefano.pileri@unibo.it. 
has been highlighted in AITL, whereas a much more heterogeneous one has been described in PTCL/ NOS. 2,3,9,10 Such differences are paralleled by a different organization of the lymphoma-associated microenvironment. Indeed, the presence of high-endothelial venule proliferation, follicular dendritic cell hyperplasia, and large B-cell and granulocyte infiltration characterize AITL allowing histopathological distinction from PTCL/NOS. ${ }^{8}$

The tumor-associated microenvironment is a complex network of cellular and molecular interactions in which cells of the innate and adaptive immunity play a primary role. In this setting, a specific subset of $\mathrm{T}$ lymphocytes, the regulatory T-cells (Treg), has been demonstrated to actively influence the immunological environment associated to neoplasms by hindering anti-tumoral immunity. ${ }^{11,12}$ The recent evidence of a functional plasticity of Treg, along with the identification of interleukin (IL)-17producing Th cells (Th17) that can differentiate from Treg and are active in promoting inflammation and autoimmunity, added a further degree of complexity to the issue of the tumor/environment interactions. ${ }^{13,14}$

To date, studies investigating the reciprocal contribution of Treg and Th17 to PTCL-associated environment are lacking. Here we studied the involvement of Tregs and Th17 in the composition of AITL and PTCL/NOS microenvironment. We found a prevalence of Th17 cells in AITL cases, and correlated it with the preferential accumulation of mast cells in this lymphoma. We suggest a possible mechanism through which AITL lymphoma cells could recruit mast cells and in turn favor Th17 polarization.

\section{Materials and Methods}

\section{Cell Lines, Reagents, and Antibodies}

The human B-cell lymphoma cell line BJAB (Epstein Barr Virus noninfected) was maintained in RPMI supplemented with $10 \%$ heat-inactivated fetal bovine serum in a humid atmosphere at $37^{\circ} \mathrm{C}$ and $5 \% \quad \mathrm{CO}_{2}$ with $50 \mathrm{U} / \mathrm{ml}$ penicillin and $50 \mu \mathrm{g} / \mathrm{ml}$ streptomycin. All reagents were from EuroClone s.p.a. (Pavia, Italy). The human LAD2 mast cell line was kindly provided by $\mathrm{A}$. Kirshenbaum $(\mathrm{NIH}$, Bethesda, MD). The cell line was established from bone marrow aspirates of a patient with mast cell (MC) leukemia. ${ }^{15}$ LAD2 cells were cultured in the serum-free medium StemPro-34 (Invitrogen, Carlsbad, CA) containing $2 \mathrm{mmol} / \mathrm{L}$ glutamine and $100 \mathrm{ng} / \mathrm{ml}$ human stem-cell factor (Peprotech Inc, Rocky Hill, NJ). The human endothelial ADMEC cells were a kind gift of F. Tedesco, Department of Life Sciences, University of Trieste (Trieste, Italy).

For immunohistochemical and immunofluorescence assays, the following primary antibodies were adopted: mouse anti-human Foxp3 (clone 221 D/D3, AbD Serotec, Oxford, UK), rabbit anti-human IL-17 (H-132, Santa Cruz Biotechnology, Santa Cruz, CA), goat anti-human IL-6 (R\&D Systems, Minneapolis, MN), rabbit anti-human IL-21 (AbD Serotec), mouse anti-human IL-23 (clone HLT 2736, Biolegend, San Diego, CA), mouse anti-human mast cell tryptase (clone 10D11, Novocastra, Newcastle,
UK), mouse anti-human OX40 (clone 102H6, Novocastra), mouse anti-human CD4 (clone IF6, Novocastra), and mouse anti-human CD25 (clone 4C9, Novocastra).

\section{Sample Selection}

PTCL/NOS and AITL cases for tissue microarray (TMA) preparation were collected from the archives of the Hematopathology Unit of the Department of Hematology and Oncological Sciences, University of Bologna (Bologna, Italy). Overall, 34 PTCL/NOS and 39 AITL cases were included in the study. Moreover, nine representative AITL and nine PTCL/NOS cases were selected from the archives of the Department of Human Pathology of the University of Palermo to perform full-section detailed immunophenotypical characterization of Th17-related cytokines, double immunohistochemistry and immunofluorescence assays, and co-localization analyses.

\section{Tissue Microarray Preparation}

For TMA construction, a H\&E-stained slide was cut from each paraffin-block and reviewed by two experienced hematopathologists (P.P.P. and S.A.P.). Representative tumor regions were morphologically identified and marked on the H\&E-stained slides. Tissue cylinders with a diameter of 1 $\mathrm{mm}$ were punched from the marked areas of each block and brought into a recipient paraffin block by using a precision instrument (Beecher Instruments, Silver Spring, MD) as previously described. ${ }^{16}$ To overcome the problem of tissue heterogeneity, each donor tissue block was punched twice. Sections 4- $\mu \mathrm{m}$ thick were cut from each TMA and transferred to electrically charged slides.

\section{Immunohistochemical Analyses}

Single-marker immunohistochemistry was performed by using the streptavidin-biotin-peroxidase complex method (Strept-ABC) as previously reported. ${ }^{17}$ Either aminoethylcarbazole (red signal) or 3,31-Diaminobenzidine (DAB; brown signal) was used as a chromogenic substrate, and sections were counterstained with hematoxylin. Negative control stainings were performed by using mouse, rabbit, or goat immune sera instead of the primary antibodies (Supplemental Figure S1 at http://ajp.amjpathol.org).

Double immunostaining was achieved by two consecutive single rounds of immunohistochemistry by using Strept$\mathrm{ABC}$ and alkaline phosphatase anti-alkaline phosphatase methods with DAB and FastRed (Dako, Glostrup, Denmark) chromogens, respectively. Slides were evaluated under a Leica DM2000 optical microscope (Leica Microsystems, Wetzlar, Germany) and microphotographs were collected by using a Leica DFC320 digital camera (Leica Microsystems).

Cell counts were visually performed on immuno-stained TMA slides by counting the absolute number of immunoreactive cells out of four high-power fields (HPF; 400× magnification) on each tissue core and then averaging the counts of the two cores. Microvascular density (MVD) was similarly assessed by counting the absolute number of $\mathrm{CD}^{+} 4^{+}$vascular structures. All of the cell counts on TMA were 
independently performed by two pathologists (C.T. and A.M.F.), and when the counts were discordant, the final score was determined by averaging the individual scores.

$\mathrm{MC} / \mathrm{Th} 17$ co-localization analysis was performed on full-sections of the selected representative nine AITL and nine PTCL cases following double-immunostaining for mast cell tryptase and IL-17. To analyze the spatial colocalization between mast cells and Th17 cells, in each case four HPFs rich in MCs (ie, representative of the highest MC density) and four HPFs almost devoid of MCs were identified; the number of Th17 cells in these areas was determined and the correlation between MC and Th17 counts was calculated.

\section{Immunofluorescence and Confocal Microscopy}

For immunofluorescence analysis on confocal microscopy, the tissue sections were deparaffinized with xylene and rehydrated to water through a graded alcohol series. After microwave antigen retrieval, the samples were incubated, by sequential immunostaining, with primary antibodies anti-human IL-6 and anti-human Tryptase. After Fc blocking, anti-IL-6 binding was revealed by Alexa 488-conjugated rabbit anti-goat (Invitrogen Molecular Probes, Carlsbad, CA) secondary antibody, and Tryptase was revealed by Alexa 568-conjugated rat antimouse (Invitrogen Molecular Probes) secondary antibody. Nuclear staining was performed by incubation with TOTO3 iodide (Invitrogen Molecular Probes). Slides were evaluated by using a Leica TCS SP5 laser scanning confocal microscope (Leica Microsystems).

\section{Quantitative RT-PCR for CXCR3 and CXCR5}

Total RNA was extracted from $10^{7}$ cells by using Trizol reagent (Invitrogen), following the manufacturer's recommendations. CDNA was obtained by using iscript cDNA Synthesis kit (Bio-Rad, San Francisco, CA) starting from 1 $\mu \mathrm{g}$ total RNA following the manufacturer's instructions. CDNA generated was amplified by quantitative real-time PCR (with Bio-Rad iQ5 instrument) using IQTM SYBR Green Super Mix (Bio-Rad), and data analysis was performed by using iQ5 optical system software (Bio-Rad). Glyceraldehyde-3-phosphate dehydrogenase (GADPH) gene was used as normalizer in each sample. Primers were designed with National Center for Biotechnology Information (NCBI)Primer Blast and sequences are as follows: GADPH forward: 5'-ACCACAGTCCATGCCATCAC-3'; GADPH reverse: 5'-TCCACCACCCTGTTGCTGTA-3'; CXCR3 forward: 5'-CATGGTCCTTGAGGTGAGTGA-3'; CXCR3 reverse: 5'TACAGCTAGGTGGAGCAGGAAG-3'; CXCR5 forward: 5'-CAGCCATGAACTACCCGCTAA-3'; CXCR5 reverse: 5'-GGCAGAGATGATTTTCCACCAG-3'.

\section{Chemotaxis Assay}

Chemotaxis was performed in a 96-transwell insert (Costar, Lowell, MA) with 8- $\mu \mathrm{m}$ pore-size filters. In addition, $1 \times 10^{5} \mathrm{BJAB}$ or LAD2 cells were plated in the upper chamber and chemoattracted by increasing concentrations of human recombinant CXCL13 (Peprotech). After 2 hours, 6 hours, and 24 hours, cell numbers in the upper and lower chamber were counted and migration was calculated as the percent of migrated cells over total cell count.

\section{Gene Expression Analysis}

We analyzed gene expression profile (GEP) data of 28 PTCL/NOS and six AITL derived from cryo-preserved lymph nodes, and four samples of reactive lymph-nodes, previously generated by using the Affymetrix HG-U133 2.0 plus microarray (Affymetrix, Inc., Santa Clara, CA) and available at http://www.ncbi.n/m.nih.gov/projects/ geo/, last accessed April 2010. For technical details see Piccaluga et al. ${ }^{9}$ In particular, we focused on the expression of selected cytokines known to be involved in Th17 polarization, such as IL-1b, IL-6, IL-17, IL-21, and IL-23. In addition, the Th1 and Th2 cytokines interferon- $\gamma$ and IL-4 were studied for control purposes. To avoid the possible puzzling effect of reactive components contained in tumor samples, cases with a content of neoplastic cells possibly higher than or equal to the $90 \%$ value were selected.

\section{Statistical Analysis}

Comparison of data between AITL and PTCL/NOS cases was performed by Student's $t$-test for independent samples assuming statistical significance for $P$ values below 0.05 . Covariate analysis was performed by the means of Spearman's rank correlation coefficient (rho).

\section{Results}

\section{IL-17 ${ }^{+}$but Not Foxp3 ${ }^{+} T$ Cells Are Differentially Represented in AITL and PTCL/NOS Cases}

We analyzed the presence and amount of $\mathrm{Foxp}^{+}$and $\mathrm{IL}-17^{+}$cells in PTCL/NOS and AITL cases counting the total number of stained cells out of four HPFs in TMAs. Overall, 37 out of 39 AITL and 30 out of 34 PTCL/NOS cases proved adequate for immunohistochemistry quantitative analysis.

As already observed by Bonzheim et $\mathrm{al}^{1{ }^{18}} \mathrm{Foxp}^{+}$ cells showed a scattered distribution in AITL and PTCL/ NOS cases and none of the evaluated cases displayed a uniform reactivity to anti-Foxp3, supporting the reactive nature of Treg infiltrating these lymphomas. A similar distribution was displayed also by IL-17-expressing cells.

The amount of Foxp3 ${ }^{+}$cells proved to be comparable in the two lymphoma subtypes as the average number of reactive cells was 35.8 (SD, 17.37) and 34.4 (SD, 15.92) in PTCL/NOS and AITL, respectively $(P=0.927$; Figures 1 and 2, A and C). Interestingly, the frequency of $\mathrm{IL}-17^{+}$cells was significantly higher in AITL (average, 10.02; SD, 5.28) than in PTCL/NOS TMAs (average, 3.07; SD, 2.34; $P=$ 0.001; Figures 1 and 2, B and D). Consequently, the average ratio between $\mathrm{Foxp}^{+}$and $\mathrm{IL}-17^{+}$cells resulted higher in PTCL/NOS than in AITL cases (9.61 vs. 4.16; $P<0.001$ ). Double immunohistochemistry and immunofluorescence for CD25/Foxp3 and CD4/IL-17 confirmed the Treg phenotype 


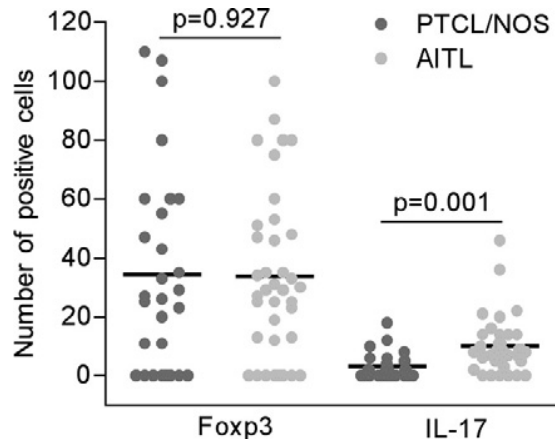

Figure 1. Frequency of Foxp $3^{+}$and $\mathrm{IL}-17^{+}$cells in $30 \mathrm{PTCL} / \mathrm{NOS}$ and 37 AITL cases. The amount of Foxp $3^{+}$cells is comparable in the two lymphoma subgroups, whereas that of $\mathrm{IL}-17^{+}$cells is significantly higher in AITL.

of infiltrating Foxp3 ${ }^{+}$cells and the T-helper phenotype of IL-17-expressing cells (not shown).

\section{Expression of Th17-Related Cytokines in AITL and PTCL Samples}

Differentiation of human Th17 cells is the product of the concomitant activity of several cytokines derived from effector and regulatory immune cells both contributing to the establishment of a pro-inflammatory environment. These cytokines include transforming growth factor (TGF)- $\beta$, IL-1 $\beta$, IL-6, IL-21, and IL-23. Specifically, a key role in inducing Th17 cells is played by IL-6, which is able to counter TGF- $\beta$-driven regulatory T-cell program toward IL-17 production, whereas IL-21 and IL-23 seem to be mainly involved in the expansion and stabilization of Th17 cells rather than in their induction. ${ }^{19}$

The finding of a higher frequency of IL-17-expressing cells in AITL cases as compared with PTCL/NOS ones prompted us to investigate the expression of the key cytokines implicated in the induction and maintenance of IL-17-producing Th cells in the two lymphoma groups. We thus analyzed the expression of IL-6, IL-21, and IL-23
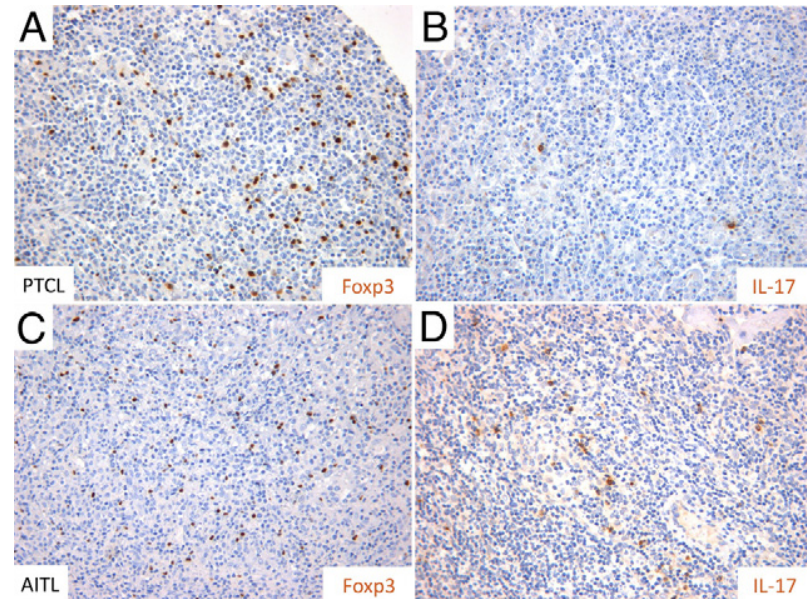

Figure 2. A and $\mathbf{C}$ : Immunohistochemical expression of Foxp3 in two representative cases of PTCL/NOS (A) and AITL $(\mathbf{C})$ showing the scattered distribution of immunoreactive cells. B and $\mathbf{D}$ : By immunohistochemistry, IL-17-expressing cells display a scattered distribution and different frequency in PTCL/NOS (B) and AITL (D) cases (Strept-ABC method with DAB chromogenic substrate; original magnification, $\times 100)$.

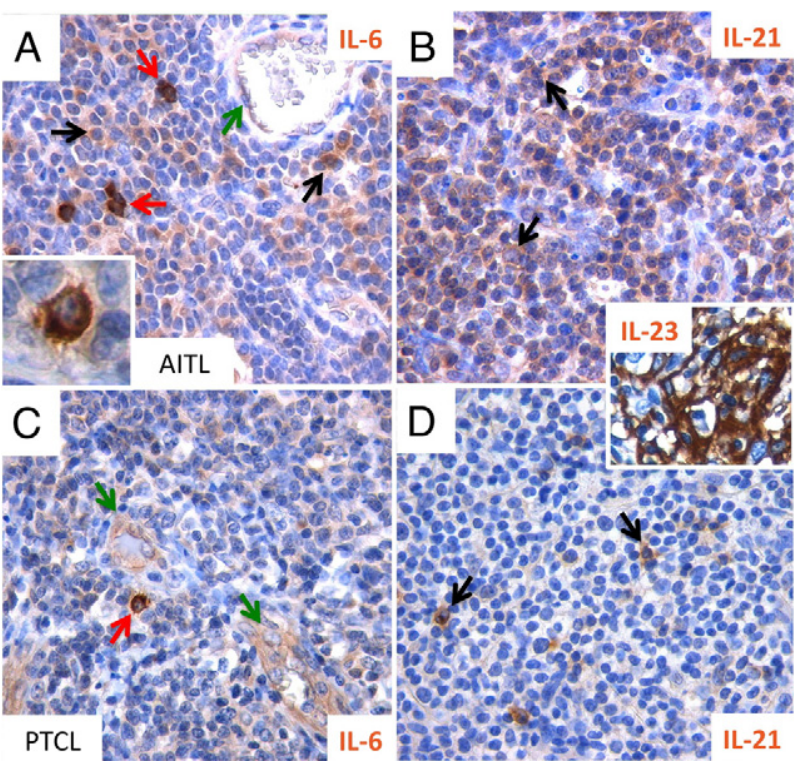

Figure 3. Immunohistochemical expression of IL-6 (A and C), IL-21 (B and D), and IL-23 (inset) in representative AITL and PTCL/NOS cases. A and $\mathbf{C}$ : IL-6 is expressed by vascular endothelia (green arrows), small lymphoid cells (black arrows), and large cells showing intense staining (red arrows, inset). B and D: IL-21 is diffusely expressed in AITL cells, whereas its expression is confined to scattered lymphoid cells in PTCL/NOS (black arrows). Inset: IL-23 expression is mainly confined to the dendritic cell/ macrophage meshwork (Strept-ABC method with DAB chromogen; original magnification, $\times 200$; inset, $\times 400)$.

by immunohistochemistry on TMAs, and extended such analysis to full-sections from the selected representative nine AITL and nine PTCL/NOS cases.

Interestingly, in both AITL and PTCL/NOS samples, IL-6 was detected in medium-sized lymphoid cells showing a dim expression (Figure $3, \mathrm{~A}$ and $\mathrm{C}$, black arrows), in vascular endothelia (Figure 3, A and C, green arrows), and in scattered large cells with round-to-oval morphology, which stained strongly with anti-IL-6 (Figure 3, A and $\mathrm{C}$, red arrows and inset). These latter cells showed a difference in terms of frequency between AITL and PTCL/ NOS, being more abundant in AITL. A diffuse staining for IL-21 was observed in lymphocytes from AITL cases (Figure 3B, black arrows), whereas reactivity was confined to scattered cells in PTCL/NOS cases (Figure 3D, black arrows). Finally, IL-23 staining proved to be confined to the Follicular Dendritic Cells (FDC) meshwork (Figure 3, inset) in AITL cases and in areas with a higher content of macrophages or foci of residual FDC in PTCL/ NOS ones.

On the basis of these results, we could conclude that the environment of AITL is permissive for the induction and expansion of Th17 cells since IL-6, IL-21, and IL-23 are expressed. Moreover, the finding of a higher fraction of cells with intense IL-6 reactivity in AITL suggested that IL-6 could represent a clue for the preferential Th17 infiltration in AITL.

\section{Differential mRNA Signatures in AITL and PTCL/NOS Include Th17-Related Cytokines}

Based on our data of the immunophenotypical expression of IL-17 and other cytokines related with Th17 po- 

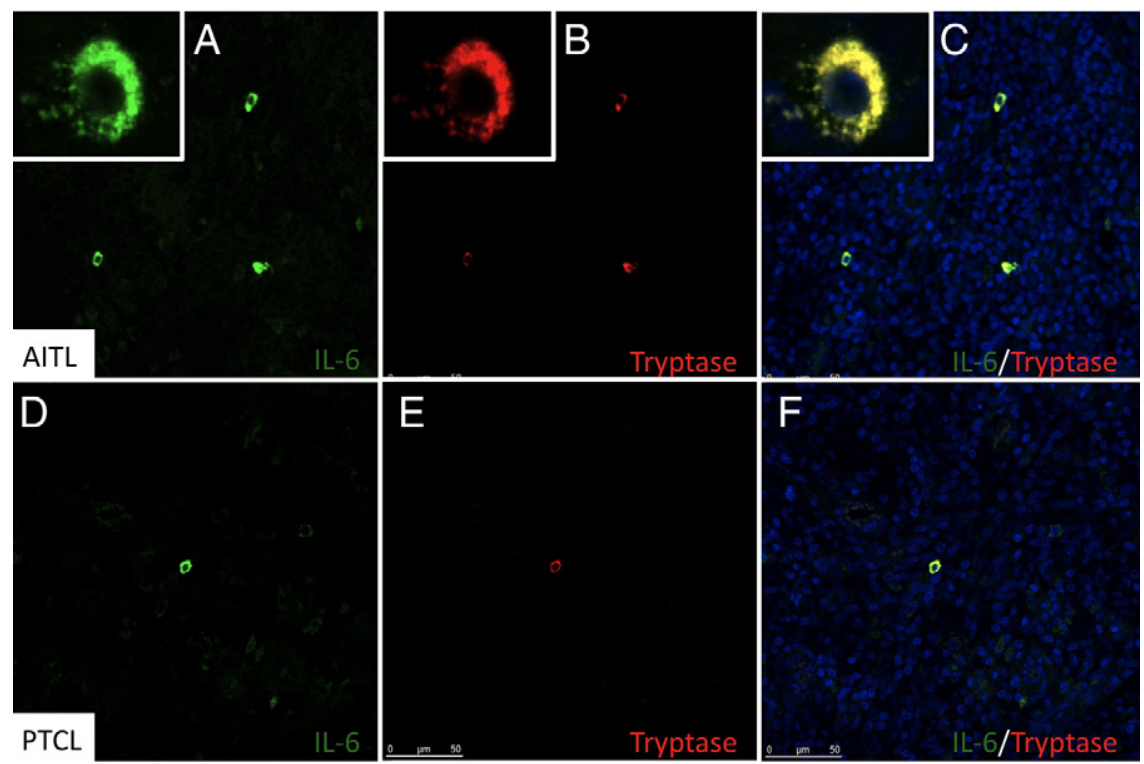

Figure 4. Double immunofluorescence confocal microscopy for IL-6 and mast cell tryptase showing that cells with bright IL-6 expression (A and $\mathbf{D}$ ) are reactive to tryptase ( $\mathbf{B}$ and $\mathbf{E})$. Coexpression of the two markers is evidenced by signal overlap (C and F). Release of IL-6 and tryptase from a degranulating mast cells is shown in the inset (double indirect immunofluorescence using Alexa 488-conjugated [green signal] and Alexa 568-conjugated [red signal] secondary antibodies; original magnifications: $\times 200[\mathbf{A}-\mathbf{F}], \times 1000$ [inset]). Microphotographs are relative to two representative AITL $(\mathbf{A}-\mathbf{C})$ and PTCL/NOS (D-F) cases. larization, we investigated whether the expression of such key cytokines was related to the AITL and PTCL/ NOS signatures. To this purpose, we first analyzed the GEPs previously generated from 28 representative cases of PTCL/NOS and six cases of AITL ${ }^{9,20}$ by focusing on the mRNA expression of IL-1 $\beta, \mathrm{IL}-6, \mathrm{IL}-17$, IL-21, and IL-23. In addition, analysis of the Th1 and Th2 cytokines interferon- $\gamma$ and IL-4 was performed for control purposes.

The GEP analysis identified detectable levels of such cytokines but failed to reveal significant differences in their expression between PTCL/NOS and AITL. Nevertheless, slightly higher values of IL-21 were recorded in AITL cases (Supplemental Figure S2 at http://ajp.amjpathol.org). Similar results were observed by looking at the differential molecular signatures of AITL and PTCL/NOS recently described by de Leval et al. ${ }^{10}$ However, as GEP from our cases actually relied on the neoplastic component, representing more than $90 \%$ of the total cellularity in the vast majority of cases, ${ }^{9}$ it is likely that the influence of reactive components, including MCs and reactive T-lymphocytes, was indeed limited. Importantly, when we considered a recently published unselected series, which included cases with abundant reactive components, the mRNA signature differentiating AITL and PTCL/NOS cases actually included the cytokines $\mathrm{IL}-6, \mathrm{IL}-21$, and $\mathrm{IL}-23{ }^{21}$ Taken together, these results further supported the evidence that Th17-related cytokines, though not belonging to the AITL and PTCL/NOS clone signatures, were an expression of different microenvironmental dynamics.

\section{Mast Cells Represent a Relevant Source of IL-6 in AITL}

We and others have recently demonstrated that mast cells are able to directly interact with regulatory T-cells giving rise to a complex bidirectional influence, which in turn can affect both the effector function of MCs and Treg suppressive program. ${ }^{22,23}$ In inflammatory conditions we showed mast cells reverting the anergic and suppressive status of Treg eventually promoting Th17 skewing through IL-6 production and the OX40-OX40L axis. ${ }^{23}$ In light of these evidences, we explored whether the medium-to-large cells, characterized by strong IL-6 expression on immunohistochemistry and found differentially present in AITL and PTCL/NOS, were mast cells. To this purpose, double immunofluorescent confocal microscopy analysis was performed by using anti-IL-6 and antimast cell tryptase antibodies. Strikingly, the population of scattered cells with bright IL-6 expression showed coexpression of mast cell tryptase, whereas cells with dim IL-6 reactivity did not (Figure 4, A-F). This result suggested that a relevant source of IL-6 in AITL was represented by mast cells, and that they likely accounted for the differential fraction of IL-6-producing cells observed in AITL and PTCL/NOS.

\section{Mast Cells Preferentially Infiltrate the AITL Environment and Correlate with the Amount of Th17 Cells}

To confirm the observation that mast cells, as IL-6 expressing cells, were more abundant in AITL as compared with PTCL/NOS samples, we evaluated the number of tryptase ${ }^{+}$cells by immunohistochemistry on TMAs. As expected, a significantly higher number of tryptase ${ }^{+}$ mast cells was detected in AITL (average, 9.06; SD, 7.69) than in PTCL/NOS (average, 2.94; SD, 2.69) samples $(P=0.013$; Figure 5, A-D), and many PTCL/NOS cases did not show the presence of infiltrating mast cells.

Subsequently, to test the relationship between the amount of infiltrating mast cells and the presence of Th17 cells, the correlation between tryptase ${ }^{+}$and $\mathrm{IL}-17^{+}$cells was investigated by covariate analysis. The correlation between tryptase ${ }^{+}$and Foxp $3^{+}$cells and that between

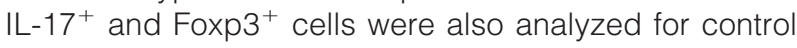
purposes.

No association was found between $\mathrm{IL}_{-1} 7^{+}$and Foxp3 ${ }^{+}$ cells (rho $=-0.107 ; P=0.391$ ) or between triptase ${ }^{+}$and 


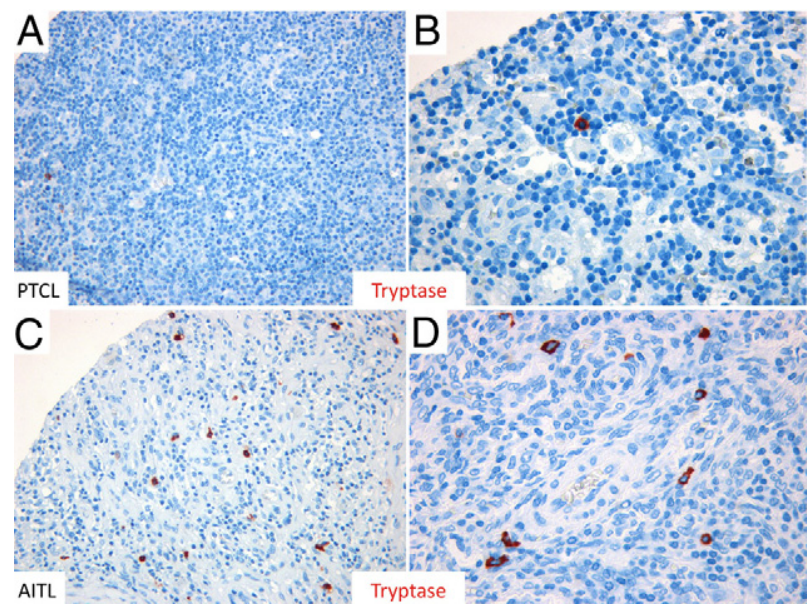

Figure 5. Amount and distribution of infiltrating mast cells in AITL and PTCL/NOS cases. A significantly higher number of tryptase-expressing mast cells are observed infiltrating AITL cases $(\mathbf{C}$ and $\mathbf{D})$ as compared with those infiltrating PTCL/NOS ones (A and $\mathbf{B}$ ). Mast cells display a scattered distribution and a round-to spindle morphology (Strept-ABC method with aminoethylcarbazole chromogen; original magnifications: $\times 100$ [A and $\mathbf{C}$; $\times 200$ [B and D]).

Foxp $^{+}$cells ( $r$ o $=-0.021 ; P=0.865$ ). Conversely, the amount of mast cells and Th17 proved to be tightly associated in our cases as the number of tryptase ${ }^{+}$cells and that of $\mathrm{IL}-17^{+}$cells showed a high degree of correlation (Spearman's rho $=0.737 ; P<0.0001$; Figure $6, A-C$ ).

Besides the association with IL-17-expressing cells, we decided to test MC correlation with the degree of MVD in AITL and PTCL/NOS samples, as MCs are known to participate in tissue remodelling processes, directly influencing angiogenesis through the release of vascular endothelial growth factor and tumor necrosis factor. ${ }^{24}$ The MVD resulted significantly higher in AITL as compared with PTCL/NOS cases (mean, 40.28; SD, 17.41; and mean, 22.57; SD, 11.09, respectively; $P=0.0001$ ). Although a significant association was observed between the number of MCs and the MVD, this association proved quite weak (rho $=0.242 ; P=0.02$ ), suggesting that the pro-angiogenic spur was mainly derived by cellular components other than MCs (Figure 6D).

Th17 cells, classically related to granulocyte dominated responses, might exert direct local effects on the lymphoma microenvironment including that of favoring granulocyte infiltration and vascular sprouting. ${ }^{25,26}$ We thus estimated the amount of infiltrating granulocytes in AITL and PTCL/NOS samples and tried to correlate it with the amount of Th17 cells. Similarly, we tested the association between Th17 cells and the MVD.

Granulocytes, as assessed by CD15 immunohistochemistry, were more numerous in AITL than in PTCL/ NOS cases (mean, 40.06; SD, 25.67; and mean, 28.68; $\mathrm{SD}, 16.55$, respectively) though such difference was slightly significant $(P=0.041)$. Interestingly, the number of $\mathrm{CD} 15^{+}$granulocytes and that of $\mathrm{IL}-17^{+}$cells proved to be strongly related (rho $=0.806 ; P<0.0001$; Figure 6E). By contrast, the fraction of Th17 cells was not associated with the microvascular density ( $r$ o $=0.242 ; P=0.062$ ).

These data, along with the evidence of a significant IL-6 production by mast cells, were indicative of a con-
A

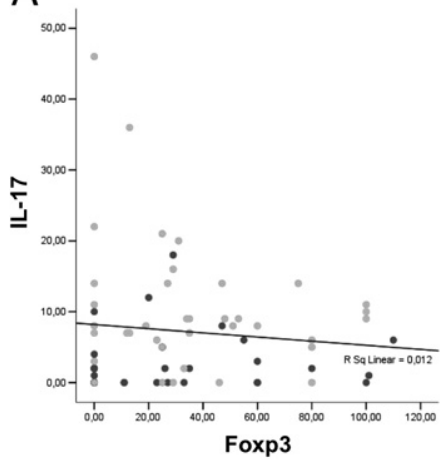

D

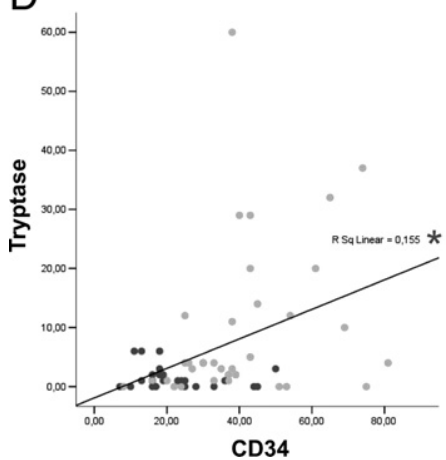

B

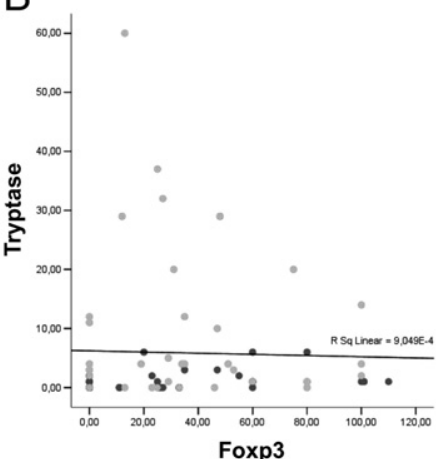

E

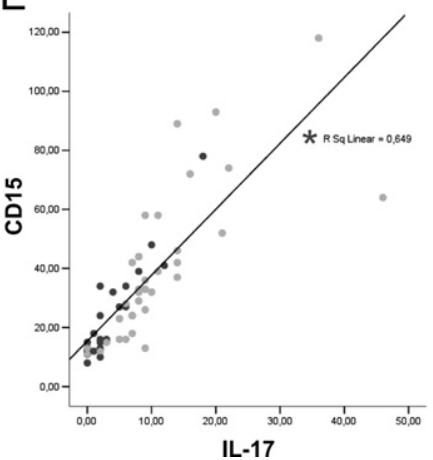

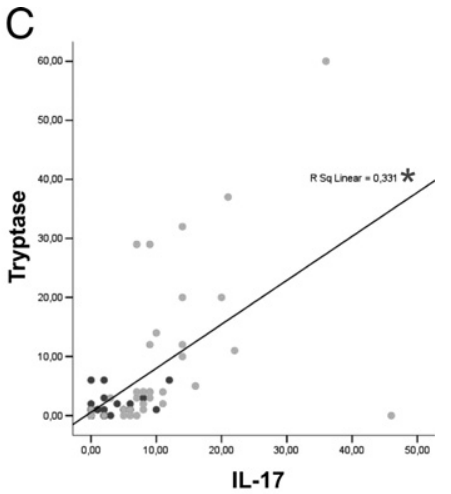

IL-17
AITL

PTCL/NOS

- best fit

* significant association

Figure 6. Analysis of the associations among regulatory T-cells (Foxp3), Th17 (IL-17), mast cells (tryptase), granulocytes (CD15), and microvascular density (CD34). A strong linear correlation is found between Th17 and mast cells and between Th17 and granulocytes, whereas the association between mast cells and microvascular density is slight. Regulatory T-cells do not show significant associations with any of the other variables. 

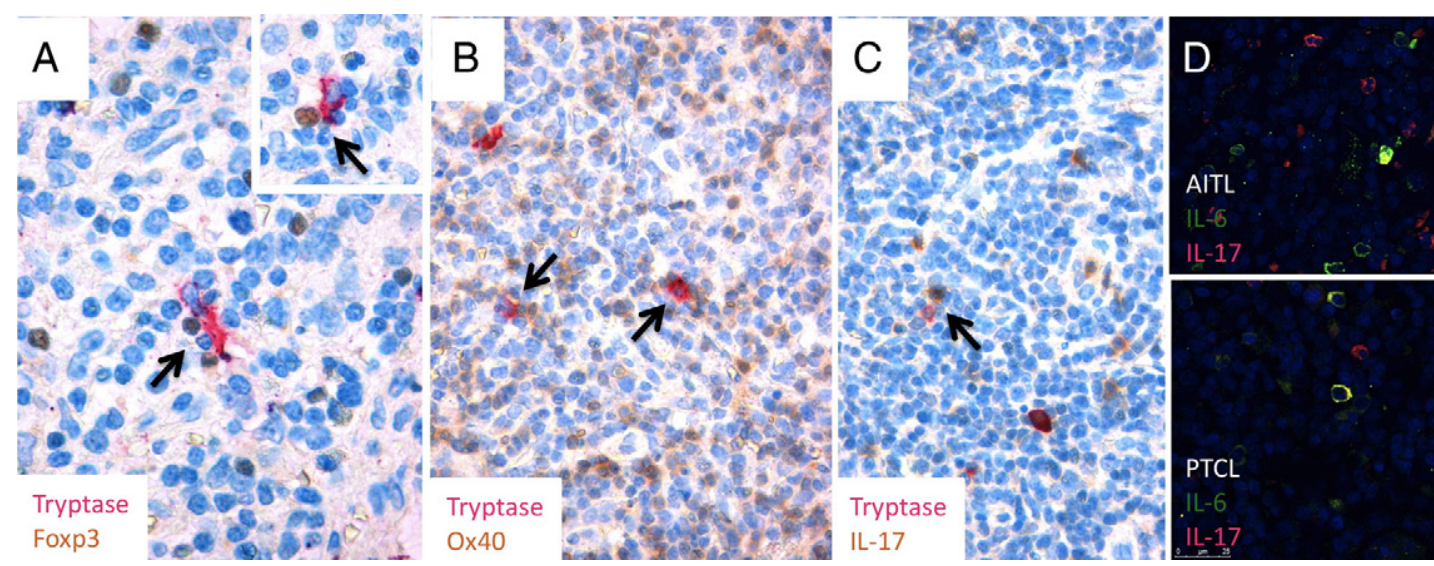

Figure 7. A: Tryptase ${ }^{+}$mast cells display cell-cell contact with Foxp3-expressing regulatory T-cells (black arrows). B: Lymphocytes surrounding mast cells express OX40, suggesting that interactions between mast cells and neighboring T cells can be complemented by OX40 engagement. C: Few mast cells are found in close contact with IL-17-expressing cells (black arrow). D: A higher density of both IL-6-expressing and IL-17-expressing cells are observed in AITL (upper panel) than in PTCL/NOS (lower panel) cases, but spatial contact between these two cell types is rarely observed. Pictures are relative to two representative AITL and one PTCL/NOS cases. A-C: Double immunohistochemistry using alkaline phosphatase anti-alkaline phosphatase and Strept-ABC methods with Fast-red (purple) and DAB (orange/brown) chromogens, respectively. D: Double indirect immunofluorescence using Alexa 488-conjugated (green signal) and Alexa 568-conjugated (purple signal) secondary antibodies. Original magnifications: $\times 400(\mathbf{A}) ; \times 200(\mathbf{B}-\mathbf{D})$.

tribution of mast cells in molding the immunological microenvironment of AITL by affecting the balance between regulatory and $\mathrm{IL}-17$-producing $\mathrm{T}$ cells.

To further elucidate this hypothesis, the tissue distribution and reciprocal relationship of MCs, regulatory T-cells, and $\mathrm{IL}-17^{+} \mathrm{T}$ cells were investigated by immunohistochemistry and immunofluorescent confocal microscopy on full sections from nine representative AITL cases. The scattered tryptase $^{+}$MCs were frequently found in close contact with one or more Foxp3 ${ }^{+}$regulatory T-cells indicating the occurrence of cell-cell interactions between these two cell types in AITL (Figure 7A). Moreover, lymphocytes in close contact with MCs commonly expressed OX40, suggesting that the effects of MC-derived IL-6 on neighboring cells could be complemented by OX40 engagement from OX40L expressed on MCs (Figure 7B). Consistently, IL-17-expressing cells were found in proximity to MCs but direct cell contact was rarely observed (Figure 7C). This was suggested also by double immunofluorescence for IL-6 and IL-17, which highlighted IL-17-expressing cells intermingling with IL-6 ${ }^{+}$ones and preferentially accumulating in AITL cases (Figure 7D). To further confirm that an actual co-localization between MCs and Th17 occurred, a spatial co-localization analysis was performed on full sections that were double-immunostained for tryptase and IL-17. We assessed the number of Th17 cells out of eight HPFs comprising four HPFs rich in MCs (indicated as "High MC" in Figure 8) and four HPFs almost devoid of MCs (indicated as "Low MC" in Figure 8). In the nine AITL cases, MCs and Th17 cells proved to be spatially associated (rho $=0.854 ; P<0.001$ ) as microscopic fields with high $\mathrm{MC}$ densities showed higher Th17 counts than those with low MC numbers, which were accordingly poor in Th17 cells (Figure 8A; see also Supplemental Figure S3 at http://ajp.amjpathol.org). A similar trend was observed in the nine representative PTCL/NOS cases (Figure 8B), though the association proved weak and barely significant (rho $=0.281 ; P=0.041$ ), this being consistent with the abovementioned very low prevalence of Th17 and MCs in PTCL/NOS.

\section{CXCL-13 Is a Candidate for Mast Cell Accumulation in the AITL Environment}

We found that the differential IL-6 expression and Th17 frequency between AITL and PTCL/NOS was related to the abundance of MCs in the former. However, the reasons for such a preferential MC accumulation in AITL were obscure. Recent evidences clearly indicate that the AITL neoplastic clone originates from Tfh cells, a subset of Th cells characterized by selective homing properties and germinal-center associated marker expression (ie, CD10 and $\mathrm{Bcl}-6){ }^{10,20}$ Tfh cells reside in the follicle where they provide crucial co-stimulatory signals to B-cells undergoing antigen presentation. Among the features proper of Tfh cells are the expression of PD-1, ICOS, CXCR5, and the abundant synthesis of CXCL-13, a potent chemoattractor for $\mathrm{B}$ lymphocytes that has been demonstrated to be essential for germinal-center formation. ${ }^{27}$ CXCL-13 mediates expansion of follicular dendritic cells and recruitment of B-cells in the germinal center and exerts an autocrine feedback on Tfh cells through the interaction with its high-affinity receptor CXCR5. Since the synthesis of CXCL-13 is maintained in the AITL neoplastic clone, we investigated whether CXCL-13 could be responsible for MC recruitment at sites of infiltration in AITL cases. To address this issue, we first examined the expression of the CXCL-13 receptors, CXCR3 and CXCR5, by real-time PCR on the human mast cell line LAD2 by using as positive and negative controls the BJAB B-cell lymphoma cell line and ADMEC cells, respectively. Significant mRNA expression of CXCR5, and to a lesser extent of CXCR3, was detected in LAD2 cells, and it was slightly lower than that of control BJAB cells (Figure 9). 
A $\quad$ MC / Th17 co-localization analysis on 9 AITL cases
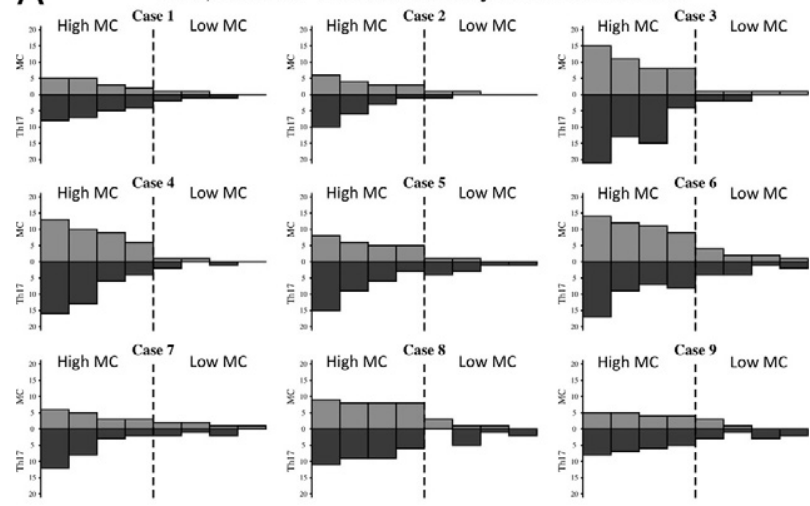

$\mathrm{MC}$ number

Th-17 number

B $\quad \mathrm{MC} / \mathrm{Th} 17$ co-localization analysis on 9 PTCL/NOS cases
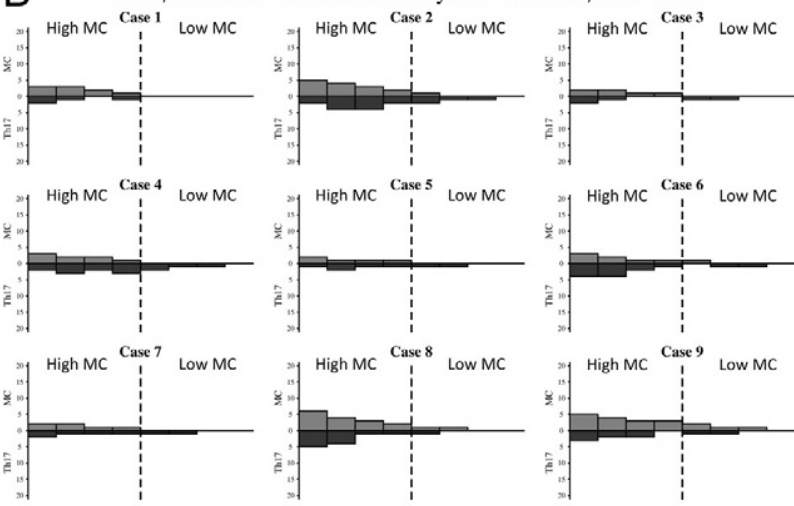

MC number

Th-17 number

Figure 8. Results of the $\mathrm{MC} / \mathrm{Th} 17$ co-localization analysis performed on full sections from nine AITL (A) and nine PTCL/NOS (B) cases following double immunostaining for mast cell tryptase and IL-17. In each case, the number of MCs (light green and light blue bars) and Th17 cells (dark green and dark blue bars) is reported as assessed in four HPFs with easily countable MCs (indicated as "High MC") and in four HPFs almost devoid of MCs (indicated as "Low MC"). In AITL cases (A) the spatial association between MCs and Th17 was evident as HPFs rich in MCs displayed higher Th17 counts than those almost devoid of MCs. Conversely, in PTCL/NOS cases (B), this picture was less evident owing to the paucity of MCs and Th17 cells.

We thus evaluated the capability of LAD2 cells to migrate in response to $C X C L-13$. The chemotaxis assay showed that CXCL-13 successfully induced LAD2 mast cell migration already at the 6 hours time point at a concentration of $10 \mathrm{ng} / \mathrm{ml}$ (Figure 10A). CXCL-13-in-

Real time PCR

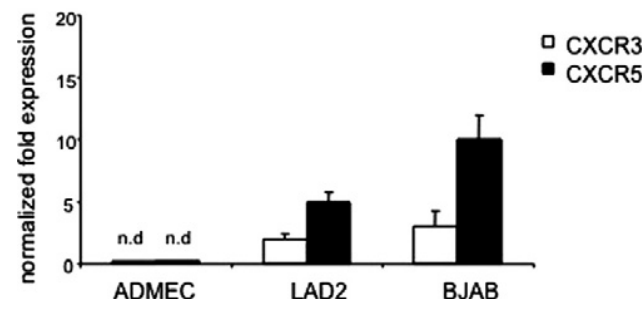

Figure 9. CXCR3 and CXCR5 expression in the human LAD2 mast cell line. CXCR3 and CXCR5 mRNA levels in ADMEC, BJAB, and LAD2 cells were determined by quantitative real-time PCR. Normalized fold expression represents the concentration ratio between the specific chemokine and the housekeeping mRNA (GADPH). Data are the mean \pm SD of two separate experiments; n.d., nondetected amplificate.

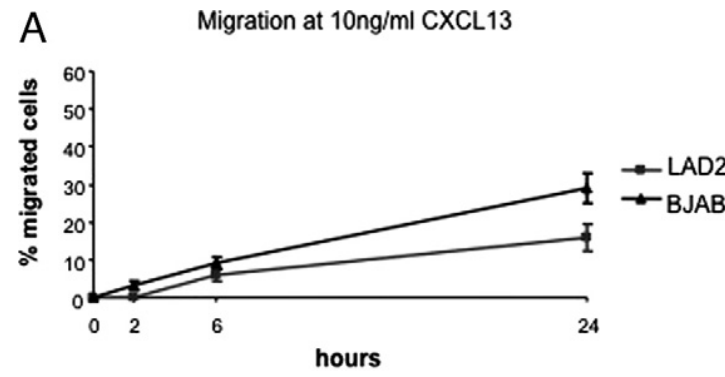

B Migration at $100 \mathrm{ng} / \mathrm{ml} \mathrm{CXCL13}$

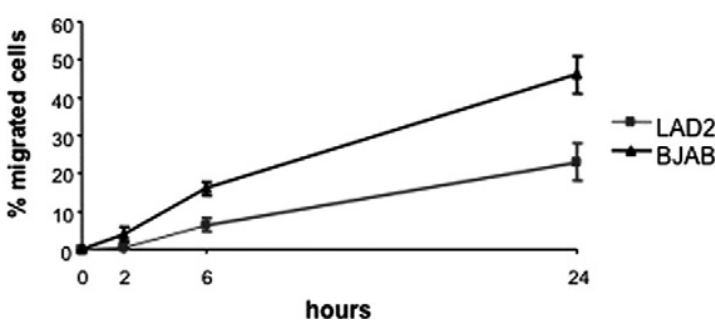

Figure 10. Dose and time response of BJAB and LAD2 cells to CXCL-13 induced chemotaxis. Chemotaxis of BJAB and LAD2 cells to $10 \mathrm{ng} / \mathrm{ml}(\mathbf{A})$ and $100 \mathrm{ng} / \mathrm{ml}$ (B) recombinant human CXCL13 at indicated time points is shown. Data represent mean \pm SD of two separate experiments performed in triplicate.

duced LAD2 cell migration was enhanced at higher concentrations of CXCL-13 and at the 24 hours time point, with a percentage of LAD2 migrating cells slightly lower than that of BJAB cells (Figure 10B). These results suggest that CXCL-13 is a possible mediator of the preferential accumulation of MCs in the AITL environment.

\section{Discussion}

The neoplastic clone and the non-neoplastic components of the tumor microenvironment are linked by a dense network of cellular and molecular interactions. The variety of such interactions can either contribute to the anti-tumor host response or even foster tumor growth. ${ }^{28-30}$ Different tumor types are associated with different microenvironments, and the environment-related gene signatures have recently emerged as key determinants in the prognostic assessment of several hematological neoplasms. ${ }^{31,32}$ In most lymphoid malignancies, the composition of the microenvironment endorses also a diagnostic significance since it represents one of the main histopathological features. In the setting of mature T-cell lymphomas, the extreme morphological variability of the T-cell clone makes the distinction between AITL and PTCL/NOS quite difficult. The histopathological and immunophenotypical detection of the peculiar features of the AITL microenvironment is then of great help. ${ }^{8}$

The most relevant clinical characteristic of AITL is the high frequency of autoimmune manifestations. These include skin rash, polyarthritis, pleural effusion, autoimmune hemolytic anemia, and thrombocytopenia, all suggestive of a marked dysregulation of the T-cell immune response. $^{33,34}$ 
The Th1/Th2 paradigm has been recently reshaped by the identification of a subpopulation of IL-17-producing Th cells whose key role is the induction of autoimmune responses. ${ }^{19}$ Studies on the generation of Th17 cells highlighted the influence of the immunological environment on the functional plasticity of T lymphocytes as Th17 cells can be induced from naive and regulatory $T$ cells under the pressure of pro-inflammatory stimuli. ${ }^{35,36}$ The required combination of TGF- $\beta$ and IL-1 $\beta$, IL-6, and/or IL-21 for Th17 induction and expansion suggests that Th17 generation is a matter of balance between pro- and anti-inflammatory signals and that in a pro-inflammatory background even cells with regulatory functions have a share in triggering autoimmunity.

In this study we assessed the frequency of regulatory and IL-17-producing T cells in PTCL/NOS and AITL to test the hypothesis of a different participation of such cell types in the composition of the lymphoma-associated microenvironment. We found a higher number of infiltrating Th17 cells in AITL than in PTCL/NOS cases, whereas the number of $\mathrm{Foxp}^{+}$Treg in the two lymphomas was similar. Accordingly, IL-6, IL-21, and IL-23 cytokines involved in the generation, expansion, and maintenance of Th17 cells were more represented in AITL than in PTCL/ NOS. Moreover, the finding of a strong association between Th17 cells and the amount of infiltrating granulocytes supported a role for Th17 cells in influencing the composition of the inflammatory microenvironment of AITL lymphomas.

Recently, our group and others demonstrated distinct molecular features in AITL and PTCL/NOS neoplastic clones by GEP analysis. ${ }^{2,9,10}$ In particular, genes belonging to the AITL signature were associated to cell-cell adhesion and communication, immune response, and vascular biology. 2,9,10,37 In the present study, we could not detect significant differences between AITL and PTCL/NOS cases as far as Th17-related cytokine patterns are concerned at mRNA level. This fact, in our opinion, probably reflected the original case selection, ${ }^{2,9}$ which included only cases almost exclusively constituted by neoplastic cells, thus limiting the influences of reactive components. Consistent with this hypothesis, differences in IL-6, IL-21, and IL-23 expression were recently recorded in other series, which included nonselected samples sometimes enriched in reactive elements. ${ }^{21}$ Taken together such observations suggest that some microenvironmental dynamics are likely responsible for cytokine enrichment in AITL.

IL-6-mediated signals in a TGF-b rich environment can determine Th17 skewing. ${ }^{19,34}$ We found MCs strongly expressing IL-6 and preferentially accumulating in AITL. MCs showed cell-cell proximity with $\mathrm{Foxp}^{+}$and OX40expressing cells and displayed a significant numeric and spatial correlation with Th17 cells. MCs have a high degree of functional plasticity ${ }^{38}$; they synthesize a broad array of molecules with either pro- (eg, IL-6 and tumor necrosis factor- $\alpha$ ) or anti-inflammatory (eg, IL-10) properties and release them according to the type and strength of the environmental signals they sense. ${ }^{39}$ Though classically confined to the role of effectors in allergic responses, MCs are emerging as master regulators of both innate and adaptive immunity as they play different roles in the induction, amplification, maintenance, and shutdown of physiological and aberrant responses. ${ }^{40-42}$ We and others have recently described the existence of a bidirectional influence between MCs and regulatory T-cells in which the OX40/OX40L axis and soluble mediators are contributing either to the maintenance of self tolerance or to autoimmunity. ${ }^{22,23}$ In the setting of autoimmunity, we demonstrated the role of MCs in the initiation of the pathological immune response in EAE (the murine model of multiple sclerosis) through the suppression of Treg cells and their skewing into pathogenic Th17 cells. ${ }^{23}$ On these bases, we could speculate on the involvement of MCs in fostering the pro-inflammatory environment of AITL through the production of IL-6 and the direct interaction with regulatory and effector T-cells predisposing their shift to Th17 cells. Grippingly, elevated IL-6 serum levels have been recorded in patients with AITL, further supporting the role of the IL-6 axis in the establishment and maintenance of the lymphomaassociated inflammatory milieu. ${ }^{43-45}$

Although the actual magnitude and the final effects of the interactions underlying the different composition of

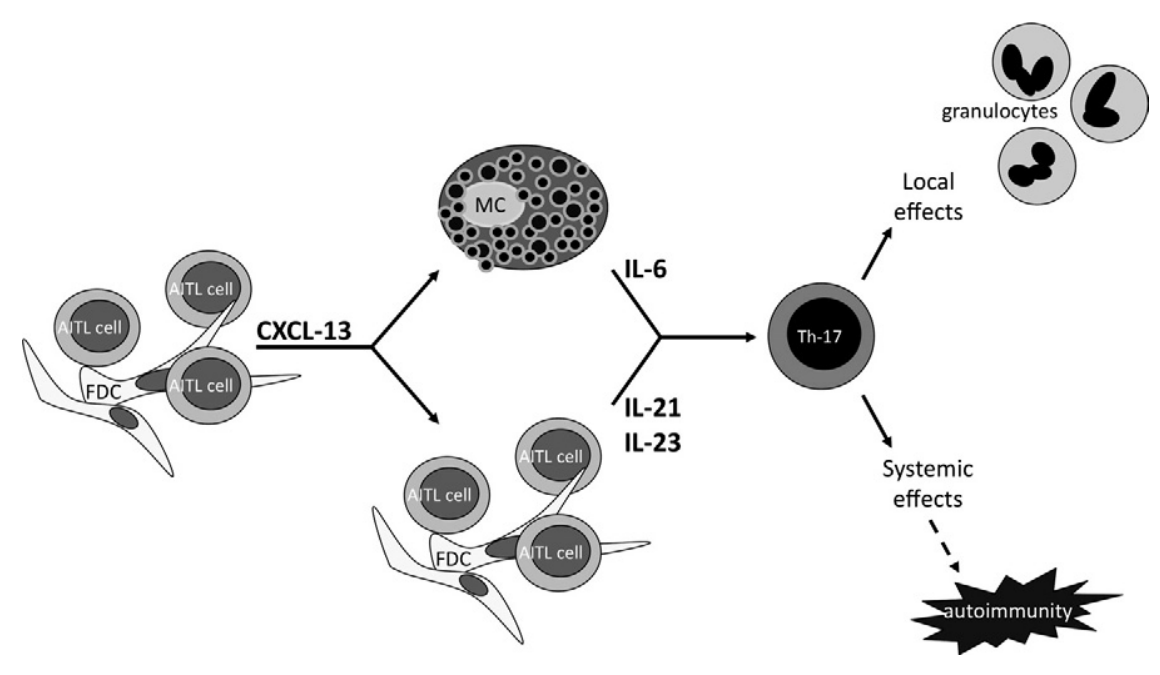

Figure 11. A schematic representation of the dynamics taking place in the AITL microenvironment. AITL neoplastic cells and FDC secrete CXCL-13 contributing to the recruitment of MCs and to FDC hyperplasia. MC-derived IL- 6 , along with AITL-clone-derived IL-21 and FDC-synthesized IL-23 contribute to the preferential generation of Th17 cells, which in turn favor granulocyte accumulation and possibly trigger autoimmune phenomena. 
the immunological microenvironment of AITL and PTCL/ NOS are obscure, the higher frequency of Th17 cells we observed in AITL cases could possibly fit with the preferential occurrence of autoimmune disorders in these patients. ${ }^{37}$ Such disorders involve the binding of IL-17 to its receptors widely distributed on parenchymal cells and the interaction of Th17 cells with other immune effectors such as polymorphonuclear leukocytes that in our cases proved tightly associated with Th17 cells. ${ }^{19,46}$

In this work we also showed that CXCL-13, the primary chemokine produced by normal Tfh cells, FDCs, and by AITL neoplastic cells, is able to induce migration of MCs as they express both CXCR5 and CXCR3 receptors. The abundant production of CXCL-13 by the AITL neoplastic clone could likely be responsible for the preferential accumulation of MCs in the AITL environment. Besides having a share in the generation of Th17 cells, MCs could affect the AITL environment through the production of pro-angiogenic molecules such as vascular endothelial growth factor and tumor necrosis factor thus contributing to the deregulated angiogenesis mostly driven by the neoplastic-clone derived vascular endothelial growth factor. ${ }^{47}$ However, the low degree of correlation we observed between MCs and the MVD is in favor of a marginal role for MCs in the arrangement of the vascular network of these lymphomas. Moreover, MCs could participate into FDC expansion and maturation since MC exosomes have been reported to induce maturation and activation of dendritic cells. ${ }^{48}$

In conclusion, we have shown that the immunological microenvironment of AITL, differently from that of PTCL/ NOS, is characterized by the abundance of mast cells likely recruited by $\mathrm{CXCL}-13$, produced, at least in part, by the neoplastic clone of Tfh derivation. In the AITL environment, infiltrating MCs might promote inflammation tipping the balance between immune regulation and autoimmunity and contributing to the local changes occurring in AITL-infiltrated tissues (Figure 11). The possible clinical relevance of microenviromental patterns as well as the potential therapeutic impact of strategies interfering in such dynamics surely warrant further investigation.

\section{References}

1. Vose J, Armitage J, Weisenburger D; International T-Cell Lymphoma Project: International peripheral T-cell and natural killer/T-cell lymphoma study: pathology findings and clinical outcomes. J Clin Oncol 2008, 26:4124-4130

2. de Leval L, Bisig B, Thielen C, Boniver J, Gaulard P: Molecular classification of T-cell lymphomas. Crit Rev Oncol Hematol 2009, 72:125-143

3. de Leval L, Gaulard P: Pathobiology and molecular profiling of peripheral T-cell lymphomas. Hematology Am Soc Hematol Educ Program 2008:272-279

4. Agostinelli C, Piccaluga PP, Went P, Rossi M, Gazzola A, Righi S, Sista T, Campidelli C, Zinzani PL, Falini B, Pileri SA: Peripheral T cell lymphoma, not otherwise specified: the stuff of genes, dreams and therapies. J Clin Pathol 2008, 61:1160-1167

5. Carbone A, Gloghini A, Cabras A, Elia G: Differentiating germinal center-derived lymphomas through their cellular microenvironment. Am J Hematol 2009, 84:435-438

6. Wilcox RA, Wada DA, Ziesmer SC, Elsawa SF, Comfere NI, Dietz AB, Novak AJ, Witzig TE, Feldman AL, Pittelkow MR, Ansell SM: Mono- cytes promote tumor cell survival in T-cell lymphoproliferative disorders and are impaired in their ability to differentiate into mature dendritic cells. Blood 2009, 114:2936-2944

7. Khokhar FA, Payne WD, Talwalkar SS, Jorgensen JL, Bueso-Ramos CE, Medeiros LJ, Vega F: Angioimmunoblastic T-cell lymphoma in bone marrow: a morphologic and immunophenotypic study. Hum Pathol 2010, 41:79-87

8. Dogan A, Gaulard P, Jaffe ES, Ralfkiaer E, Muller-Hermelink HK: Angioimmunoblastic T-cell lymphoma. WHO classification of tumours of the haematopoietic and lymphoid tissues. Edited by SH Swerdlow, E Campo, NL Harris, ES Jaffe, SA Pileri, H Stein, J Thiele, JW Vardiman. Lyon, IARC Press, 2008, pp 309-311

9. Piccaluga PP, Agostinelli C, Califano A, Rossi M, Basso K, Zupo S Went P, Klein U, Zinzani PL, Baccarani M, Dalla Favera R, Pileri SA: Gene expression analysis of peripheral T cell lymphoma, unspecified, reveals distinct profiles and new potential therapeutic targets. J Clin Invest 2007, 117:823-834

10. de Leval L, Rickman DS, Thielen C, Reynies A, Huang YL, Delsol G, Lamant L, Leroy K, Brière J, Molina T, Berger F, Gisselbrecht C, Xerri L, Gaulard P: The gene expression profile of nodal peripheral T-cell lymphoma demonstrates a molecular link between angioimmunoblastic T-cell lymphoma (AITL) and follicular helper T (TFH) cells. Blood 2007, 109:4952-4963

11. Zou W: Regulatory T cells, tumour immunity and immunotherapy. Nat Rev Immunol 2006, 6:295-307

12. Wang HY, Wang RF: Regulatory T cells and cancer. Curr Opin Immunol 2007, 19:217-223

13. Lee YK, Mukasa R, Hatton RD, Weaver CT: Developmental plasticity of Th17 and Treg cells. Curr Opin Immunol 2009, 21:274-280

14. Kryczek I, Banerjee M, Cheng P, Vatan L, Szeliga W, Wei S, Huang E, Finlayson E, Simeone D, Welling TH, Chang A, Coukos G, Liu R, Zou W: Phenotype, distribution, generation, and functional and clinical relevance of Th17 cells in the human tumor environments. Blood 2009, 114:1141-1149

15. Kirshenbaum AS, Akin C, Wu Y, Rottem M, Goff JP, Beaven MA, Rao VK, Metcalfe DD: Characterization of novel stem cell factor responsive human mast cell lines LAD 1 and 2 established from a patient with mast cell sarcoma/leukemia; activation following aggregation of FcepsilonRI or FcgammaRI. Leuk Res 2003, 27:677-682

16. Tzankov A, Zimpfer A, Lugli A, Krugmann J, Went $P$, Schraml $P$, Maurer R, Ascani S, Pileri S, Geley S, Dirnhofer S: High-throughput tissue microarray analysis of G1-cyclin alterations in classical Hodgkin's lymphoma indicates overexpression of cyclin E1. J Pathol 2003, 199:201-207

17. Tripodo C, Di Bernardo A, Ternullo MP, Guarnotta C, Porcasi R, Ingrao S, Gianelli U, Boveri E, lannitto E, Franco G, Florena AM: CD146(+) bone marrow osteoprogenitors increase in the advanced stages of primary myelofibrosis. Haematologica 2009, 94:127-130

18. Bonzheim I, Geissinger E, Tinguely M, Roth S, Grieb T, Reimer P, Wilhelm M, Rosenwald A, Müller-Hermelink HK, Rüdiger T: Evaluation of FoxP3 expression in peripheral T-cell lymphoma. Am J Clin Pathol 2008, 130:613-619

19. Miossec P, Korn T, Kuchroo VK: Interleukin-17 and type 17 helper $T$ cells. N Engl J Med 2009, 361:888-898

20. Piccaluga PP, Agostinelli C, Califano A, Carbone A, Fantoni L, Ferrar S, Gazzola A, Gloghini A, Righi S, Rossi M, Tagliafico E, Zinzani PL, Zupo S, Baccarani M, Pileri SA: Gene expression analysis of angioimmunoblastic lymphoma indicates derivation from $\mathrm{T}$ follicular helper cells and vascular endothelial growth factor deregulation. Cancer Res 2007, 67:10703-10710

21. Iqbal J, Weisenburger DD, Greiner TC, Vose JM, McKeithan T, Kucuk C, Geng H, Deffenbacher K, Smith L, Dybkaer K, Nakamura S, Seto M, Delabie J, Berger F, Loong F, Au WY, Ko YH, Sng I, Armitage JO, Chan WC; International Peripheral T-Cell Lymphoma Project: Molecular signatures to improve diagnosis in peripheral T-cell lymphoma and prognostication in angioimmunoblastic T-cell lymphoma. Blood 2010, 115:1026-1036

22. Gri G, Piconese S, Frossi B, Manfroi V, Merluzzi S, Tripodo C, Viola A, Odom S, Rivera J, Colombo MP, Pucillo CE: CD4+CD25+ regulatory $T$ cells suppress mast cell degranulation and allergic responses through OX40-OX40L interaction. Immunity 2008, 29:771-781

23. Piconese S, Gri G, Tripodo C, Musio S, Gorzanelli A, Frossi B, Pedotti R, Pucillo CE, Colombo MP: Mast cells counteract regulatory T-cell 
suppression through interleukin-6 and OX40/OX40L axis toward Th17-cell differentiation. Blood 2009, 114:2639-2648

24. Kalesnikoff J, Galli SJ: New developments in mast cell biology. Nat Immunol 2008, 9:1215-1223

25. Murugaiyan G, Saha B: Protumor vs antitumor functions of IL-17. J Immunol 2009, 183:4169-4175

26. Qiu Z, Dillen C, Hu J, Verbeke H, Struyf S, Van Damme J, Opdenakker G: Interleukin-17 regulates chemokine and gelatinase B expression in fibroblasts to recruit both neutrophils and monocytes. Immunobiology 2009, 214:835-842

27. Fazilleau N, Mark L, McHeyzer-Williams LJ, McHeyzer-Williams MG Follicular helper T cells: lineage and location. Immunity 2009, 30:324-335

28. Joyce JA, Pollard JW: Microenvironmental regulation of metastasis. Nat Rev Cancer 2009, 9:239-252

29. Meads MB, Gatenby RA, Dalton WS: Environment-mediated drug resistance: a major contributor to minimal residual disease. Nat Rev Cancer 2009, 9:665-674

30. de la Cruz-Merino L, Grande-Pulido E, Albero-Tamarit A, CodesManuel de Villena ME: Cancer and immune response: old and new evidence for future challenges. Oncologist 2008, 13:1246-1254

31. Anguiano A, Tuchman SA, Acharya C, Salter K, Gasparetto C, Zhan F, Dhodapkar M, Nevins J, Barlogie B, Shaughnessy JD Jr., Potti A: Gene expression profiles of tumor biology provide a novel approach to prognosis and may guide the selection of therapeutic targets in multiple myeloma. J Clin Oncol 2009, 27:4197-4203

32. Lenz G, Wright G, Dave SS, Xiao W, Powell J, Zhao H, Xu W, Tan B, Goldschmidt N, Iqbal J, Vose J, Bast M, Fu K, Weisenburger DD, Greiner TC, Armitage JO, Kyle A, May L, Gascoyne RD, Connors JM, Troen G, Holte H, Kvaloy S, Dierickx D, Verhoef G, Delabie J, Smeland EB, Jares P, Martinez A, Lopez-Guillermo A, Montserrat E, Campo E, Braziel RM, Miller TP, Rimsza LM, Cook JR, Pohlman B, Sweetenham J, Tubbs RR, Fisher RI, Hartmann E, Rosenwald A, Ott G, MullerHermelink HK, Wrench D, Lister TA, Jaffe ES, Wilson WH, Chan WC, Staudt LM; Lymphoma/Leukemia Molecular Profiling Project: Stromal gene signatures in large-B-cell lymphomas. N Engl J Med 2008, 359:2313-2323

33. Iannitto E, Ferreri AJ, Minardi V, Tripodo C, Kreipe HH: Angioimmunoblastic T-cell lymphoma. Crit Rev Oncol Hematol 2008, 68: $264-271$

34. Mourad N, Mounier N, Brière J, Raffoux E, Delmer A, Feller A, Meijer CJ, Emile JF, Bouabdallah R, Bosly A, Diebold J, Haioun C, Coiffier B, Gisselbrecht C, Gaulard P; Groupe d'Etude des Lymphomes de l'Adulte: Clinical, biologic, and pathologic features in 157 patients with angioimmunoblastic T-cell lymphoma treated within the Groupe d'Etude des Lymphomes de l'Adulte (GELA) trials. Blood 2008, 111:4463-4470

35. Lee YK, Turner H, Maynard CL, Oliver JR, Chen D, Elson CO, Weaver
CT: Late developmental plasticity in the T helper 17 lineage. Immunity 2009, 30:92-107

36. Kitani A, Xu L: Regulatory T cells and the induction of IL-17. Mucosal Immunol 2008, Suppl 1:S43-S46

37. de Leval L, Gisselbrecht C, Gaulard P: Advances in the understanding and management of angioimmunoblastic T-cell lymphoma. $\mathrm{Br} J$ Haematol 2010, 148:673-689

38. Colombo MP, Piconese S: Polyps wrap mast cells and Treg within tumorigenic tentacles. Cancer Res 2009, 69:5619-5622

39. Sayed BA, Christy A, Quirion MR, Brown MA: The master switch: the role of mast cells in autoimmunity and tolerance. Annu Rev Immunol 2008, 26:705-739

40. Galli SJ, Grimbaldeston M, Tsai M: Immunomodulatory mast cells: negative, as well as positive, regulators of immunity. Nat Rev Immunol 2008, 8:478-486

41. Frossi B, Gri G, Tripodo C, Pucillo C: Exploring a regulatory role for mast cells: "MCregs"? Trends Immunol 2010, 31:97-110

42. Merluzzi S, Frossi B, Gri G, Parusso S, Tripodo C, Pucillo C: Mast cells enhance proliferation of $B$ lymphocytes and drive their differentiation towards IgA-secreting plasma cells. Blood 2010, 115:2810-2817

43. Yamamura M, Honda M, Yamada Y, Itoyama T, Sohda H, Yubashi T, Momita S, Kamihira S, Ohmoto Y, Tomonaga M: Increased levels of interleukin-6 (IL-6) in serum and spontaneous in vitro production of IL-6 by lymph node mononuclear cells of patients with angio-immunoblastic lymphadenopathy with dysproteinemia (AILD), and clinical effectiveness of cyclosporin A. Leukemia 1996, 10:1504-1508

44. Hashefi M, McHugh TR, Smith GP, Elwing TJ, Burns RW, Walker SE: Seropositive rheumatoid arthritis with dermatomyositis sine myositis, angioimmunoblastic lymphadenopathy with dysproteinemia-type T cell lymphoma, and B cell lymphoma of the oropharynx. J Rheumatol 2000, 27:1087-1090

45. Yamamoto $H$, Miwa $H$, Kato $Y$, Nakamura S, Hara K, Nitta M: Angioimmunoblastic $\mathrm{T}$ cell lymphoma with an unusual proliferation of Epstein-Barr virus-associated large B cells arising in a patient with progressive systemic sclerosis. Acta Haematol 2005, 114:108-112

46. Annunziato F, Cosmi L, Liotta F, Maggi E, Romagnani S: Type 17 T helper cells-origins, features and possible roles in rheumatic disease. Nat Rev Rheumatol 2009, 5:325-331

47. Zhao WL, Mourah S, Mounier N, Leboeuf C, Daneshpouy ME, Legrès L, Meignin V, Oksenhendler E, Maignin CL, Calvo F, Brière J, Gisselbrecht $C$, Janin A: Vascular endothelial growth factor-A is expressed both on lymphoma cells and endothelial cells in angioimmunoblastic T-cell lymphoma and related to lymphoma progression. Lab Invest 2004, 84:1512-1519

48. Skokos D, Botros HG, Demeure C, Morin J, Peronet R, Birkenmeier G, Boudaly S, Mécheri S: Mast cell-derived exosomes induce phenotypic and functional maturation of dendritic cells and elicit specific immune responses in vivo. J Immunol 2003, 170:3037-3045 